\title{
Informing managers about telecommunications technologies for education and training
}

\author{
Peter Hosie, Terry Charman and Roger Atkinson
}

\begin{abstract}
Australian educational technologists face the challenge of convincing management to invest in telecommunications for some important aspects of education and training. Despite well-proven overseas models and ample evidence to indicate the cost and learning effectiveness (Hosie, 1987, 1988; Lundin, 1988) of using telecommunications, Australia has been slow to take advantage of possibilities the technology offers. Why is this so?
\end{abstract}

As Lange (1984) accurately ventures: fear, apathy, lack of encouragement and ignorance are the main reasons why implementation of telecommunications technology for the delivery and administration of education and training has lagged behind in Australia. Not surprisingly these disincentives have resulted in a lack of effective policy developments. Without well researched and marketed policy there is unlikely to be forward motion.

One obvious deficiency is the lack of information and understanding of telecommunications technologies throughout the general community, including amongst lecturers, teachers and trainers. What understanding people have is fragmented, disjointed and often confused with commercial brand names. High-end applications such as video conferencing are the most known and sought after by educators and trainers. However, once awareness is raised and sources of information provided, considerable interest may be shown in alternative technologies of a simpler and more affordable nature. Often, facilities are available for use but knowledge of their application to education and training is limited. 
Educational and training administrators and policy developers in Australia could be fairly accused of all of Lange's sins in relation to developing the uses of telecommunications technology but they cannot all be overcome instantly. Also, decision-makers in education have been elevated to their management positions before these technologies became widely used. Hence management often lacks the essential base knowledge to make informed decisions.

This article arises from one of the activities of Western Australia's Telecommunications for Education and Training (TET) Task Force. One part of its work was to provide essential base-level information, in an accessible form, for education managers involved in making decisions about implementing telecommunications technology. This article is concerned with techniques for providing this kind of information.

\section{Background to the TET Task Force}

In early 1988, the Federal House of Representatives Standing Committee on Employment, Education and Training conducted an inquiry into new technology in education (Commonwealth of Australia, 1989). Western Australia's submission was derived from a number of State government departments and coordinated by the Office of Communications, Department of Computing and Information Technology (now Department of State Services) (Government of Western Australia, 1988).

Shortly after the submission was made, the Office of Communications arranged a seminar, "Communications for Education: Gateway to Educational and Training Opportunities" which was opened by the Premier of Western Australia on 29 November 1988 (Office of Communications, 1988). The Premier stressed that the key to exploiting the opportunities offered by modern communications to improve distance education is cooperation and sharing of resources and facilities on the part of both users and providers of education and training. The Office of Communications was nominated to establish a Task Force to coordinate the use of telecommunications technology for education and training, and to ensure that developments were consistent with the State Government Strategic Telecommunications Plan.

The objective of the Task Force was "to develop an enduring procedural mechanism for the effective and efficient use of telecommunications for delivering education and training in Western Australia".

Elements of education and training in the Terms of Reference of the Task Force included early childhood, primary, secondary and pre-vocational education; higher education; vocational skills training; professional development; adult education; skills upgrading; recreational education; 
continuing education. An anticipated outcome will be improved access to education for people, especially in rural and remote areas, and enhanced skills training. Serious consideration of alternative ways of delivery was deemed to be timely, coinciding with a number of reviews by the Ministry of Education, universities and many State government agencies into provisions for education and training.

The administrative telecommunications requirements of State agencies were to be considered, but not as a primary focus for the Task Force, as these services are considered by other procedures through the State's Communications Strategy Committee. The Task Force was not to be concerned with decisions about curriculum priorities and methods of delivery, these being the responsibility of the education or training providers concerned. The Task Force was to assist agencies to utilise telecommunications, identify opportunities for sharing facilities for telecommunications, and ensure that the aggregated needs of education providers are input into State telecommunications planning.

The Task Force was structured into three tiers, an "Executive Management Committee" comprising executive level representatives from the major education and training organisations and user groups, and a "Coordinating Group" overseeing the work of four "Common Purpose Groups", representing Primary and Secondary education; Post Secondary (universities and TAFE), Training and Professional Development; and Community Interest. Coordination of the Task Force was achieved by all minutes and documents being sent to the full mailing list, by members belonging to any one or more CPGs as appropriate, and by the Coordinating Group which comprised the leader of each CPG as well as other contributors with a broad interest across the activities of the Task Force.

\section{Identifying available technology}

The first of the Terms of Reference for the Task Force was to "identify available technology for the effective delivery of, and access to, education and training services". To facilitate this work, two of the authors with the assistance of some members of the Task Force prepared a rating scale and applied it to a number of technologies for educational telecommunications, as a guide for "identifying available technology".

The resulting publication (Office of Communications, 1989a) provided all members of the Task Force with a compact reference point for decisions relating to other items in the Terms of Reference. The Task Force was a large and diverse group, representing many sectors of education and training, with varying levels of experience in educational telecommunications. Under these circumstances, use of a rating scale and 
its accompanying definitions and explanations provided a basic tool for discussion within the Task Force, in addition to the direct role in relation to the first Term of Reference.

Attempts to apply any kind of rating or ranking to technologies are highly sensitive to context, particularly in educational telecommunications which tends to deploy a combination of technologies and services for each particular application. Nevertheless, for each service, technology or application, an attempt was made to provide an indicative rating. The rating scale ( 1 being lowest or least desirable or most difficult, and 5 being highest or most desirable or least difficult) was deliberately kept as simple as possible in an effort to present information which could be quickly scanned to obtain an appreciation and summary of each feature. An example of the rating scale is provided in Table 1, for talkback television, adapted from the original publication (Office of Communications, 1989a).

While the terms "low" and "high" may not represent relative measures, they do indicate extremes on a continuum. As a general guide each point was rated with both the provider (agency or teacher) and user (student) in mind. In an effort to keep the rating simple, many factors which influence the selection were combined into general headings, resulting in some loss of detail but giving improved readability.

Ratings assumed typical use in an educational or training environment. An explanation of the ratings for audio teleconferencing may be taken as a further example. Audio teleconferencing would normally take place using loudspeaker (or hands-free) telephones connected to the PSTN (Public Switched Telephone Network). For this example, assume four locations, for one hour, twice per week at an average distance from the originating caller of 85 to $165 \mathrm{~km}$, incurring a total (4 site) Telecom STD charge of $\$ 1.32$ per minute.

Note that some of the ratings illustrated in Table 1 could change significantly if a State Government network using a combination of satellite and terrestrial facilities became available, in particular the affordability factor may be improved. Introduction of new technology, for example ISDN (Integrated Services Digital Network), may have a marked effect on some of the factors.

\section{Affordability factors}

The cost of items is difficult to quantify as low cost (high affordability) to one person or organisation could be vastly different to another. As a guide, consider the ratings as follows:

(1) above $\mathrm{A} \$ 100000 ;(2) \mathrm{A} \$ 20000$ - 100 000;

(3) $\mathrm{A} \$ 5000$ - 20 000; (4) $\mathrm{A} \$ 1000$ - 5 000; (5) up to $\mathrm{A} \$ 1000$. 
Table 1: Applying the rating scale to talkback television

Talkback television is defined as the addition of a telephone link back to the studio so that the broadcast television program (either live or recorded) can be supplemented by realtime interaction.

\begin{tabular}{lccccc}
\hline Affordability factor & low & & & & high \\
\hline Initial outlay & $(1)$ & 2 & 3 & 4 & 5 \\
Recurrent & $(1)$ & 2 & 3 & 4 & 5 \\
Hardware & $(1)$ & 2 & 3 & 4 & 5 \\
Software & $(1)$ & 2 & 3 & 4 & 5 \\
Maintenance & $(1)$ & 2 & 3 & 4 & 5 \\
Additional support staff & $(1)$ & 2 & 3 & 4 & 5 \\
\hline Ease of use factor & low & & & & high \\
\hline Hardware ease of use & $(1)$ & 2 & 3 & 4 & 5 \\
Software ease of use & $(1)$ & 2 & 3 & 4 & 5 \\
Materials preparation & $(1)$ & 2 & 3 & 4 & 5 \\
\hline Access factor & low & & & & high \\
\hline Perth metropolitan area & 1 & 2 & 3 & 4 & $(5)$ \\
Country towns & 1 & 2 & 3 & $(4)$ & 5 \\
Country areas & 1 & 2 & $(3)$ & 4 & 5 \\
Remote areas & 1 & 2 & $(3)$ & 4 & 5 \\
To equipment & 1 & 2 & 3 & 4 & $(5)$ \\
\hline Teacher and learner factors & low & & & & high \\
\hline Interactivity with students & 1 & 2 & 3 & $(4)$ & 5 \\
Retention of ordinary teaching methods & 1 & 2 & $(3)$ & 4 & 5 \\
Control pace and sequence of lesson & 1 & 2 & $(3)$ & 4 & 5 \\
Review previous instructions & 1 & $(2)$ & 3 & 4 & 5 \\
Generate text & 1 & 2 & 3 & $(4)$ & 5 \\
Generate graphics & 1 & 2 & 3 & $(4)$ & 5 \\
Hear students & 1 & 2 & 3 & $(4)$ & 5 \\
See students & $(1)$ & 2 & 3 & 4 & 5 \\
Hear teacher & 1 & 2 & 3 & 4 & $(5)$ \\
See teacher & 1 & 2 & 3 & 4 & $(5)$ \\
\hline Notes for Table & & & & &
\end{tabular}

\section{Notes for Table 1}

There is a substantial network of broadcast television stations throughout Western Australia. Broadcast television can be delivered either terrestrially or by satellite. It is an effective way of reaching a wide audience. Its limitation for education and training is that it is one way only. Programs for broadcast can be pre-recorded and inserted at any time or live from a studio or remote location and relayed to the transmitter station. Generally it is unrealistic to consider two way full motion television as a suitable application for most education and training requirements. However, because most households and schools now have television reception, one-way broadcast is a useful medium for delivery of education and training programs.

One of the criticisms often levelled at broadcast television for educational use, however, is that it does not provide for interaction with its audience. While adding a telephone return link to broadcast television cannot provide the same level of interactive involvement as an audio teleconference, it can be a successful method of delivering courses. 
For the audio teleconferencing example, initial outlay of 4 loudspeaker telephones at approximately $\$ 800$ each gives a total of $\$ 3200$; assign RATING $=4$. A recurrent cost of 4 locations $\times 2 \times 40$ weeks $\times 0.36$ cents $\times 20$ hours gives a total of $\$ 2304$; assign RATING $=4$. Hardware, software and maintenance costs would be non-existent; assign RATING; $=5$. There may be a small need for additional support staff as trainers or conveners; assign RATING $=5$.

\section{Ease of use factors}

Setting up and use of hardware is fairly straightforward for audio teleconferencing. Once the telephones are properly located and the call is connected, one or more buttons are pressed on the telephone to activate loudspeakers and microphones. Assign RATING $=4$. Software ease of use is medium to high, as in theory all that is required to establish a call is a booking with the Telecom operator, which can be done as required (at least half an hour ahead of requirement) or as a regular activity permanently booked with Telecom. In practice, there are a number of complicating factors, such as waiting for all parties to be connected to the conference and not being aware of a line disconnection during the conference. Assign RATING $=4$. Preparation of materials is only marginally different to a normal classroom situation, although material needs to be properly planned and organised to minimise the use of costly time on the network; assign RATING $=4$

\section{Access factor}

Perth metropolitan area and country towns are well served by telephone facilities. Assign RATING $=5$ for both. Country areas outside of towns are less well served and may require special arrangements; $\mathrm{RATING}=3$. Remote areas often have insufficient telephone services; RATING $=2$. There is fairly easy access to equipment; assign RATING $=4$.

\section{Teacher and learner factors}

Interactivity with students is the same as any telephone call and therefore only marginally less than face to face; assign RATING $=5$. Retention of ordinary teaching methods is at a moderately high level; assign RATING = 4. The degree to which the pace and sequence of lesson can be controlled is high, requiring only moderately more pre-planning and organisation than a classroom lesson; assign RATING $=4$.

Review of previous instructions is possible but the interaction is not quite as dynamic as a traditional classroom situation; assign RATING $=4$. Text and graphics cannot be generated using this medium alone; assign RATING $=1$. Students and teachers can both be heard simultaneously; 
assign RATING $=5$ for both hear students and hear teacher factors. Neither students or teachers can be seen using this medium alone; assign RATING $=1$ for both see students and see teacher factors.

\section{Technologies and services}

The rating scale described above was applied to a number of telecommunications technologies and services for consideration by the Task Force. These were divided into broad categories. Some of the items drawn to the Task Force's attention were not strictly telecommunications devices or services but they were included as relevant to the applications of telecommunications technology in education and training delivery and administration. Also, some technologies could be placed in more than one category, but for ease of understanding their coverage was simplified. The list included (Office of Communications 1989a):

1. Broadcasting

1.1 Radio

1.2 Talkback radio

1.3 Television

1.4 Talkback television

2. Fixed/mobile radio communication

$2.1 \mathrm{HF}$ radio

2.2 Satellite mobile (Mobilesat)

3. Teleconferencing

3.1 Audio teleconferencing

3.2 Audiographic teleconferencing

3.3 Computer conferencing

3.4 Video teleconferencing

4. Peripherals

4.1 Electronic whiteboard

4.2 Facsimile

4.3 Slow scan video

4.4 Interactive video disk

5. Computer-mediated communications

5.1 Electronic mail

5.2 Videotex

5.3 Voicemail

6. Ancillary communications services

6.1 FM subcarrier

6.2 Teletext 
Summaries similar to the one illustrated in the notes to Table 1 were provided for each of these services and technologies, together with appropriate definitions of technical terms. An indication was given also on the suitability of each service for delivering education to individuals, small, medium and large classes.

Table 2: Average ratings

\begin{tabular}{lcccc}
\multicolumn{1}{c}{ Service } & $\begin{array}{c}\text { Afford- } \\
\text { ability }\end{array}$ & $\begin{array}{c}\text { Ease of } \\
\text { use }\end{array}$ & Access & $\begin{array}{c}\text { Teacher/ } \\
\text { learner }\end{array}$ \\
\hline Broadcast radio & 1.0 & 2.0 & 3.2 & 1.7 \\
Talkback radio & 1.0 & 2.0 & 3.2 & 2.5 \\
Broadcast television & 1.0 & 1.0 & 4.0 & 2.7 \\
Talkback television & 1.0 & 1.0 & 4.0 & 3.5 \\
HF radio & 4.0 & 3.7 & 2.4 & 2.7 \\
Satellite mobile (Mobilesat) & 3.7 & 4.0 & 4.0 & 3.1 \\
Audio teleconferencing & 4.2 & 4.0 & 3.8 & 3.1 \\
Audiographic teleconferencing & 3.2 & 2.3 & 3.4 & 3.9 \\
Computer conferencing & 4.2 & 3.3 & 3.6 & 2.6 \\
Video conferencing & 1.5 & 1.7 & 2.6 & 4.6 \\
Electronic mail & 4.5 & 3.7 & 3.6 & 2.2 \\
Voicemail & 3.3 & 4.0 & 3.4 & 2.6 \\
\hline
\end{tabular}

Table 2 shows some average ratings. Such broad brush information cannot be used in any specific way for a particular application, but it was important for members of the Task Force to be fully aware of the major factors and perceptions of these factors held by persons in other sectors of education and training.

In addition to summarised information of the type illustrated in Tables 1 and 2, the Task Force received a range of literature and demonstrations of telecommunications services. A number of television programs discussing technologies in education were broadcast via the Golden West Network, holder of the State's Remote Commercial Television Service licence, during its educational broadcasting times, and provided on video tapes to the Task Force members.

A wide range of submissions were made to the Task Force, giving information about services and technologies and also promoting the interests behind some specific applications. For example, the Royal Flying Doctor Service detailed its role as the provider of the five high frequency radio base stations which are used in teleconferencing style by the State's School of the Air for isolated children. Other submissions included a proposal for a Remote Area Public Radio Service, to be carried by spare capacity the State had available on an Aussat transponder, which would give statewide broadcasting from a number of local public radio stations; 
discussion papers on the organisation of services for open learning; accounts of technologies in use and services hoped for at the State's Distance Education Centre, provider of primary and secondary level distance education; and other matters. Office of Communications staff provided reports on visits and surveys conducted in remote areas.

\section{Applications and resource sharing}

As a result of these activities the TET Task Force did not lack information on the technologies available, and the kinds of services which can be built upon those technologies. For example, a particular technology such as satellite transmission can provide a number of services, including television broadcasting, radio broadcasting and video conferencing. However, applications of these technologies and services, for example for providing primary education to isolated school children, are very much dependent upon the creation of ways to share telecommunications resources. In the Western Australian context featuring very small, widely dispersed centres in a vast state, facilities as expensive as satellite transceivers or video conferencing studios at present cannot be afforded for any single application to meet the needs of just one particular department of the State Government, or one particular sector of education.

The second of the Terms of Reference for the Task Force was to "identify opportunities for sharing telecommunications resources and facilities". In this respect, learning about the needs and capabilities of other sectors and departments is at least equally as important as learning about technologies. Much attention was given to this matter (Skelton, 1990) for it was perceived to hold the key to improved applications of the technologies and services studied by the Task Force.

However, information about technologies and services, and knowledge of opportunities to create viable applications based upon resource sharing across departments and sectors, do not by themselves guarantee that the desired outcomes will occur. Desired outcomes, for example the avoidance of closures of schools in sparsely settled districts and many other cases, have to be articulated, promoted and related to the technological tools. The flow of information from potential clientele has to be added to the flow of information from the technologists in education and training.

\section{Acknowledgment}

This paper is based upon a publication by the Office of Communications for the TET Task Force (Office of Communications, 1989a), now out of print. If there is sufficient interest, republication may be possible. 


\section{References}

Commonwealth of Australia (1989). An Apple for the Teacher? Choice and Technology in Learning. Report of the House of Representatives Standing Committee on Employment, Education and Training. Canberra: AGPS.

Hosie, P. J. (1987). Satellites and education in Australia - learning from international experience. British Journal of Educational Technology, 18(1), 60-76. http:/ / dx.doi.org/10.1111/j.1467-8535.1987.tb00663.x

Hosie, P. J. (1988). Realistic uses of Aussat for distance education in Western Australian primary and secondary schools. Distance Education, 9(1), 27-47

Government of Western Australia (1988). Inquiry Into New Technology in Education, July 1988: A Submission by the Government of Western Australia. Perth: Government of Western Australia.

Lange, J. C. (1984). 12 Issues in Australian Tertiary Telecommunications. Paper presented to the RMIT Conference. Satellite Communications in Australian Tertiary Education, pp.1-21.

Lundin, R. (1988). Communication and Information Technologies in Business and Education. Brisbane: Brisbane College of Advanced Education (now Queensland University of Technology).

Office of Communications (1988). Communications for Education: Gateway to Educational and Training Opportunities. Perth: Department of Computing and Information Technology (now Department of State Services).

Office of Communications (1989a). Appropriate Telecommunications Services, Technologies and Applications for Education and Training. Perth:

Department of Computing and Information Technology (now Department of State Services).

Office of Communications (1989b). Access to Education and Training: Action Plan. Perth: Department of Computing and Information Technology (now Department of State Services).

Skelton, P. (1990). Edtel: access to education and training. In R. Atkinson and C. McBeath (Eds), Open Learning and New Technology: Conference Proceedings, 294-298. Perth: Australian Society for Educational Technology WA Chapter. http: / / www.ascilite.org.au/asetarchives / confs/olnt90/skelton.html

Authors: Peter Hosie is now with The University of Western Australia, after working previously as Executive Officer for the TET Task Force. Terry Charman, now at the Commonwealth Department of Transport and Communications, was previously Policy Officer with the Office of Communications, Department of Computing and Information Technology. Dr Roger Atkinson is Senior Lecturer in Distance Education, External Studies Unit, Murdoch University, Murdoch Western Australia 6150 (address for correspondence).

Please cite as: Hosie, P., Charman, T. and Atkinson, R. (1991). Informing managers about telecommunications technologies for education and training. Australian Journal of Educational Technology, 7(2), 117-126. http: / / www.ascilite.org.au/ajet/ajet7/hosie.html 